\title{
sciendo
}

DOI: 10.2478/orga-2021-0008

\section{The Role of Daily Affect in Leader- Member Exchange: A Multilevel Investigation in Public Health Administration}

\author{
Mehmet ÇETIN ${ }^{1}$, Gulmira SAMENOVA ${ }^{2}$, Filiz TÜRKKAN², \\ Ceylan KARATAŞ ${ }^{2}$
}
${ }^{1}$ Istanbul Sabahattin Zaim University, Faculty of Business and Management Sciences, İstanbul, Turkey, mehmet.cetin@izu.edu.tr (corresponding author)

2 İstanbul Sabahattin Zaim University, Graduate Education Institute, İstanbul, Turkey, samenova.gulmira@std.izu. edu.tr, turkkan.filiz@std.izu.edu.tr, ceylankaratas88@gmail.com

\begin{abstract}
Background and purpose: Although the critical role of affect in the leader-member relationship has been widely accepted, few studies investigated the impact of within-person affect variations in daily leader-member exchange (LMX) or addressed potential cross-level and intra-individual moderators of this relationship. This study examines the effects of followers' positive and negative affect on their daily LMX in public health care organizations. The moderator roles of emotional labor and trait emotional intelligence were also investigated.

Methodology: A multilevel research design was conducted where daily measures were nested in individuals. Seventy participants working in a government health organization operating in Istanbul responded to daily surveys for five consecutive workdays (350 day-level responses) and a general survey one week after the daily data collection period (70 person-level responses). Hypotheses were tested using Hierarchical Linear Modeling (HLM).

Results: Both positive affect and negative affect were positively related with LMX (day-level), but negative affect had a negative association with LMX on the inter-personal level (when daily scores were averaged across days). Although trait emotional intelligence showed a positive cross-level effect, none of the proposed moderations was significant.

Conclusion: The role of affect in LMX development is critical and has a complex structure. Findings emphasize the importance of multilevel research for understanding the affect-LMX relationship as they demonstrate different pictures in day-level and person-level analysis.
\end{abstract}

Keywords: Positive affect, Negative affect, Emotional labor, Leader-member exchange, Trait emotional intelligence, Day-level interaction

\section{Introduction}

The importance of public healthcare organizations in the service sector and the economy has been growing in Turkey since the introduction of the health transformation program in 2003, which brought sound quality and capac- ity improvements in the public health care system (Bener et al., 2019). Public hospitals constitute the leading service provider role (having the majority of bed capacity) in Turkey's total health care system (Dundar et al., 2010). All over the World, public health organizations have been facing complex and substantial leadership challenges (Shickle et al., 2014). In the public health care context, the extent

Received: 4th February 2021; revised: 6th May 2021; accepted: 11th May 2021 
of the responsibility and the severity of the outcomes of any possible mistakes are highly critical. In addition, requirements for effective management during intense crises and the demanding nature of the job regarding the regulation of affects in the workplace make affective structures and leader-member relationships crucial for public health administration.

The significance of affect in social exchange and role-making processes has been widely recognized by organizational behavior scientists (Cropanzano et al., 2017a). The term "affect" in organizational behavior studies refers to emotions people experience and transform into work environments while interacting with others (Brief \& Weiss, 2002). Favorable emotions like enthusiasm, joy, happiness, etc., comprise positive affect, whereas sadness, fear, shame, and similar feelings form negative affect. Affective events theory (AET) underscores the role of feelings in the formation of employee attitudes and behaviors (Cropanzano et al., 2017a). Like daily affective experiences, affective trait constructs, such as trait EI, can shape organizational outcomes ( $\mathrm{Li}$ et al., 2018). Thus, a substantial number of organizational studies have scrutinized how affect shapes the interpersonal relationship and the leader-member exchange (LMX) in particular (e.g., Liu et al., 2020).

Among the leadership models investigated in the previous millennium, the LMX theory is undoubtedly one of the most fascinating. In contrast to the idea that a leader behaves equally toward all members, the LMX concept propagates a different nature of the link between a supervisor and all his/her subordinates. It is a complex process determined by long-term as well as momentary intrinsic and extrinsic elements like the personality of the leaders and the followers, their affect, job specification, cultural differences, gender, age, organizational environment, etc. (Nahrgang \& Seo, 2016; Hofmans et al., 2019). In previous decades, LMX research has been predominantly focused on leadership constructs such as leader personality and leadership style and their impact on organizational outcomes (Uhl-Bien et al., 2014). Fewer studies have investigated the follower side of the construct. In particular, the scarcity of the research is more noticeable for attempts to explain how state affective phenomena (e.g., positive and negative affect) shape followers' perception of LMX quality. Therefore, in this paper, various affect phenomena of the followers are tested to reveal their impact on LMX.

Moreover, the LMX quality is not stable and may vary in time (Ellis et al., 2019). Despite the dominance of studies addressing the construct as a stable concept, the central promise and the roots of the LMX are founded on the suggestion that the exchange and relationship between leader and followers are dynamic in nature (Hofmans et al., 2019). One of the primary triggers in LMX quality fluctuations can be the individual affective state or emotions (Liu et al., 2020). How individuals feel may change across the days, and moods and emotions are strongly tied to interpersonal exchange (Cropanzano et al., 2017b). Studies indicating intra-individual variance in affective states and LMX (Nezlek and Allen, 2006; Hofmans et al., 2019); and cross-level effects of affective constructs on interpersonal exchange in organizations (e.g., Tse et al., 2008) are supportive for the need for addressing day level variations and cross-level effects regarding study variables. The majority of studies on the affect-LMX relationship have considered it as having a static and between-person nature rather than investigating how momentary within-person variance influence the affect-LMX development. Most of the early research on affect and LMX was carried out via single-level models, and few studies have addressed the momentary within-person affect variations in leader-member exchange processes during their daily contacts (e.g., Tse et al., 2018). Thus, the current study may shed some light on the research into this matter. A more significant gap remains in investigating possible daily and person-level interactions among affect constructs and daily LMX. Addressing the aforementioned gaps, the present study analyzes the role and influence mechanisms of various day and person-level affect constructs (positive affect, negative affect, emotional labor, and trait emotional intelligence) on the perception of LMX in the work environment. In particular, the research focuses on investigating how subordinates' affective states influence their daily LMX and which individual emotional characteristics may regulate this interaction.

The outcomes of daily emotional experiences can vary according to extent and type of the emotion regulation strategy used for managing the internal state or the external expression of emotions (Costakis et al., 2021). The current study adopts Lee and Brotheridge (2011)'s conceptualization of emotional labor (EL) which defines $\mathrm{EL}$ as the reconstruction of the emotion (deep acting) or modification of its presentation (surface acting) in three dimensions (dividing the latter into two), not showing the genuine emotions (hiding feelings), changing the display of the sentiment (faking emotions) and modifying the internal emotion (deep acting). How employees regulate the NA and PA they experience during the day can affect their impact on LMX outcomes (Tse et al., 2018).

Along with the day level affect constructs (EL, NA, and PA) that are addressed at the within-person level, the current study also investigated cross-level effects of EI as a person-level affective trait variable. EI describes the capacity, tendencies, and competence to detect, internalize, realize, and finally manage emotions (Mayer \& Salovey, 1997). Thus, EI is about knowing or understanding emotions and includes using them in a functional way (regulation and management of emotions), which makes this construct essential for the present study. Among different conceptualizations that have been provided for EI in the literature, 'ability EI' (assessing EI as a competence through performance tests) and 'trait EI' (assessing EI as 
a personality structure through self-reports) approaches are prevalent (see, O'Connor \& Little, 2003). Petrides \& Furnham (2001) underscore the significance of the measurement method for the operational definition of the concept and suggest a self-report, dispositional measurement approach instead of assessing the performance (ability). In line with the present study aims, following Petrides and Furnham (2001), EI is conceptualized as a trait that describes the behavioral tendencies and self-perceived personal characteristics.

This study aims to contribute to the extant knowledge on the affect-LMX relationship through a multilevel nested research design. Mainly, study aims to investigate the person-level and intra-individual level effects of positive affect (PA) and negative affect (NA) on LMX. The direct (cross-level) effect and moderator effect of trait emotional intelligence (EI) and emotional labor (EL) (hiding, faking, and deep acting) on this association are also examined.

The multilevel investigation of the affective antecedents of daily LMX is critical to study due to several reasons. First, LMX is a determinant for numerous critical employee attitudes, behaviors, and organizational outcomes specially in health care organizations (Shickle et al., 2014; Ürek \& Uğurluoğlu, 2019). Thus, the research on the development and antecedents of this concept is precious. Second, despite their importance for organizations, the affective antecedents of LMX remain understudied. The general stream of findings addresses state-affective constructs such as positive and negative affect as consequences of LMX, and the path from affect to LMX is often neglected. Third, addressing the gap above regarding the investigation of LMX as a dynamic structure and including the intra-individual variance in the analysis can enhance the information on the matter. Lastly, the examination of possible dynamics influencing the association between daily affect and LMX can further develop our understanding regarding the nature of the affect-LMX relationship.

Built on the affective events theory, this study aims to address the aforementioned gaps and contribute to extant knowledge on the affect-LMX association through a multilevel research design where intra-individual, inter-individual, and cross-level variations and effects are investigated. This way, the study examines affect as an antecedent of daily LMX and tests cross-level and moderator effects of EI and EL in this relationship. This provides a shift for both the causality in the affect-LMX relationship and the exploration of the day-level and person-level nature of this association. Moreover, this study aims to advance our knowledge of the daily and cross-level dynamics regulating this relationship.

\section{Theoretical Framework and Construction of Hypotheses}

\subsection{Positive and Negative Affect and LMX}

Affect can be defined as emotions people show or feel during their interaction with others and during decision-making processes. It can be positive (e.g., pride, enthusiasm, joy) or negative (e.g., fear, distress, sadness). In terms of duration, affect has been considered from two viewpoints: as a trait that reflects basic feelings and is more stable over time, and as a state that is defined as the present mood/emotion that changes within-person over time (Tellegen et al., 1999). Many studies stressed the importance of affect in the development of LMX processes. Consequently, the research interest in the affect-LMX relationship has been growing since 2000 (Tse et al., 2018).

The LMX theory has its roots in Dansereau et al. (1975)'s efforts on the vertical dyad linkages theory. The authors of the theory suggested that dyadic relationships between superiors and subordinates can explain varied relationships in an organization. LMX addressed the change in the quality of the dyadic relationship between the leader and the follower over time. Dienesch \& Liden (1986) suggested a multidimensional construct for LMX consisting of perceived contribution, loyalty, and liking. Professional respect was added as the fourth dimension later (Dienesch \& Liden, 1986).

LMX is a dyadic relationship where both parts of interaction influence the exchange quality. Initially, the vast majority of the research dedicated to LMX has focused on the leader's characteristics, while follower attributes have attracted organizational behavior scientists in recent decades (Uhl-Bien et al., 2014).

In general, followers expressing positive affect (PA) are expected to develop high-quality LMX, whereas negative affect (NA) is very likely to deteriorate their relationship with leaders (Dulebohn et al., 2012). Because PA reflects the bright side of personal characteristics like enthusiasm, optimism, motivation, and engagement, leaders are likely to support followers with a high PA, and therefore, the relationship between them is expected to have higher quality (Liu et al., 2020). On the other hand, NA is associated with different kinds of negative feelings like fear, hostility, distress, exhaustion, and apathy, which foster an adverse reaction on people, situations, and interactions with others in the surrounding environment, including the workplace (Glasø et al., 2018). Subsequently, the relationship between a subordinate with high NA and his/her supervisor is assumed to be less favorable and less effective (Bernerth et al., 2007). 


\subsection{Affective Events Theory (AET)}

Individuals confront different situations within the work environment, and these conditions impact their emotions and moods (Weiss \& Cropanzano, 1996). For instance, positive or negative affect may arise in the relationship between supervisors and subordinates during daily interactions that illustrate the LMX perception. The affective events are not bounded only by organizational incidents but may include extra-work situations that change the emotional state of a person (Ashton-James \& Ashkanasy, 2008). Everyday family-related issues, as well as positive events, arouse negative or positive moods within an individual. Unconsciously, individuals transfer emotions inherited in these non-work associated conditions to their job environments and subsequently react to heterogeneous events occurring in the organization through the lens of earlier experienced emotional situations. Such affective events may influence the personal attitudes and behaviors of organizational members as well as their LMX perceptions (Cropanzano et al., 2017b).

A considerable number of the studies that address AET as the foundation of the affect-LMX relationship consider LMX an antecedent of affect and positions LMX experiences as work events. However, LMX can also be regarded as an affect-driven consequence because the theory indicates that employees' behaviors are guided by their emotions. How individuals feel reflects their behaviors and attitudes, which are fundamental elements of LMX. Cropanzano et al. (2017a), using AET for explaining the affect-LMX association, emphasized the importance of affect for the LMX development. They also highlighted the existence of alternative paths and a two-way causality where interactions with the leader shape the affective states and affects influence the LMX nature. In their metanalysis, Tse et al. (2018) demonstrated that LMX had been considered as both an antecedent and a consequence in different studies that are addressing the affect-LMX relationship.

Based on the framework mentioned above and pattern of results regarding LMX and affect, we suggest that day-level affect will influence the fluctuations in subordinates' LMX perception and propose the following hypotheses:

H1: Daily positive affect positively influences the daily LMX perception of the employees.

H2: Daily negative affect negatively influences the daily LMX perception of the employees.

\subsection{Emotional Labor, Positive Affect, Negative Affect, and Leader-Member Exchange}

Despite the different definitions of emotional labor (EL) in the organizational behavior literature, on a broad- er sense, it represents the act of showing the socially desired emotions in the service transaction processes (Hochschield, 1983). Interactions between different actors at work (client-officer, leader-subordinate, etc.) are subject to emotional experiences, and how emotions are managed during these interactions define the nature and quality of the EL construct. Two main strategies of EL are discussed in the academic literature: "Deep acting" and "surface acting" which are further divided into subgroups by different authors (Fouquereau et al., 2019).

Surface acting involves emotion simulation by expressing outward appearance like voice tone, gestures, or facial expression. The part of the surface acting when actual feelings are masked and manipulated to show socially expected expression represents the "faking emotions" dimension. When an employee does not show his/her true emotions (and not changing how it appears), it refers to "hiding feelings". Deep acting, in contrast, reflects the aligning of inner feelings by the situation. Sincere emotions, authenticity, or expression of genuine emotion is a way of the employee's natural behavior in various exchange situations (Grandey, 2000).

Different individual attributes, job features as well as organizational characteristics influence the EL strategies of a person. Therefore, affect and LMX may be considered as antecedents of EL. The affective state of an individual may define his/her EL (Lee \& Madera, 2019), and high-quality LMX can positively regulate it (Medler-Liraz, 2014). Affective events theory (AET) is one of the most frequently used theories in the research addressing emotional constructs, and it suggests that affective experiences can impact the emotional labor preferences of employees (Lee \& Madera, 2019).

EL required in the workplace can have positive or negative effects on employees. Whereas a majority of research stressed the negative influence of EL on subordinates' psychological condition and work performance (Morris \& Feldman, 1996; Wang et al., 2019), some studies underlined a positive outcome of EL on job satisfaction as well as on stress level (Xu et al., 2020). In general, extant studies reveal that deep acting promotes largely positive outcomes like job satisfaction, sincerity, or a sense of fulfillment. On the other side, surface acting triggers mainly adverse outcomes such as emotional exhaustion or dissatisfaction (Fouquereau et al., 2019). Moreover, EL strategies mitigate interpersonal processes within an organization, including a leader-member exchange. For instance, when individuals experience negative affect in the workplace, how they express or reflect it is very much related to their EL. If employees use deep acting, their NA would reflect their inner processes and their relationships with their leaders in a less destructive manner. If they engage in hiding or faking their emotions, their NA would create stronger negativity regarding their LMX.

H3: Daily EL moderates the relationship between dai- 
ly NA and daily LMX, where deep acting weakens the relationship, hiding feelings and faking emotions strengthen the link.

\subsection{Emotional Intelligence, Positive Affect, Negative Affect, and Leader- Member Exchange}

There are two main pillars of research and approach in EI literature. One view conceptualizes EI as an ability and assesses it via objective performance tests such as the performance on solving an emotional problem (e.g., Freudenthaler \& Neubauer, 2007). Other approach considers EI as a personality trait and measure it with self-report forms on behavioral tendencies, capacities, or personality characteristics (e.g., Petrides, 2009). A discussion on which operational definition or measurement is more valid has been controversial and discussed among scholars. The former approach criticized 'trait EI' as being not distinct from personality variables and suggested 'ability EI' as a better predictor for achievement. The latter conceptualization criticized the 'ability EI' approach for having some flaws and problems and suggested the 'trait approach' to EI as a better alternative. Petrides and Furnham (2001) operationalize these two concepts (trait EI and ability EI) as distinct structures instead of considering them as two different approaches to measure the same variable. They conceptualized trait EI as a composite and distinct personality construct that stands for dispositions and behavioral tendencies regarding emotional characteristics. O'Connor and Little (2003)'s and Warwick and Nettelbeck (2004)'s findings support Petrides and Furnham (2001)'s distinction in the operationalization of ability EI and trait EI as they indicate different patterns of correlations for each variable with cognitive ability and personality constructs. Trait EI can be defined as the ability, and disposition individuals perceive about themselves regarding realizing, understanding, expressing, adapting, and managing emotions effectively (Petrides and Furnham, 2001). In the current study, following Petrides and Furnham (2000, 2001), EI is conceptualized as a personality trait and assessed as a self-report person level (level 2) variable.

Despite the disputes in the social science community about the EI construct and its measurement, this phenomenon is widely applied in the relationship as well as leadership studies. The positive relationship between EI and employee engagement, work performance, job satisfaction, and commitment was demonstrated in different studies (Jordan \& Troth, 2011; Li et al., 2018; Wen et al., 2019). EI can impact how individuals' positive or negative affective states during the work processes relate to other outcomes. For instance, EI is shown to intensify the positive affect and decrease the influence of negative affect on organizational citizenship (Miao et al., 2020). Alternative- ly, people with a positive affective state are expected to regulate their EI more effectively. In contrast, a negative mood may reduce the ability of a person to understand and cope with the emotions of others.

EI is considered as an essential characteristic of leaders as well as followers in leadership research (Dasborough, 2006; Troth et al., 2018; Tse et al., 2018) and, in general, the development of high-quality social exchange between parties. Additionally, LMX has its moderating/mediating effect on EI and job outcomes (Lee et al., 2018; Ardabili, 2020). As EI refers to the capacity to realize and manage one's emotions, employees experiencing negative affect can better adjust and control their feelings to avoid negative interactions or impressions to create better LMX. Based on that assumption, this study proposes a moderating impact of EI on the relationship between NA and LMX.

H4: Trait EI will moderate the relationship between daily NA and daily LMX; as the level of trait EI increases, the negative link between daily NA and daily LMX will be weaker. In other words, daily LMX levels of employees with higher levels of trait EI will be less affected by daily NA.

\section{Method}

\subsection{Participants and Procedure}

The data for this research were collected from employees working in an administrative department of the public health organization operating in Istanbul, Turkey. A convenience sampling approach was used. The department is responsible for managing the operational and strategic functions of large-scale public hospital in the European side of Istanbul. The units are divided into three sections such as medical, financial, and administrative services. Personnel working in these units are defined as general administrative services, health services, technical services, and auxiliary services. Participants were informed about the aim and procedure of the research. Anonymity and confidentiality issues regarding the data collection process were underscored. A multilevel research design where daily affect and LMX measures were nested in individuals was used. A general (one-time) survey that contained questions asking information regarding demographics, the measure for assessing trait EI, and a code to match this survey with day-level surveys were given prior to the shorter day-level questionnaires. Two weeks after the collection of the first questionnaire, the participants were asked to fill the short surveys at the same time every afternoon during five consecutive workdays. The daily surveys collected data on LMX, EL, and negative and positive affect (with the matching code). All surveys were hand-collected in envelopes by the authors. 73 employees willingly participated in the first, one-time (second-level) survey. The surveys 
(daily and person-level) were matched by a unique personal code produced by the respondents. 70 participants provided usable five consecutive day-level responses and a person a level response each. We used 350 day-level (70 participants x 5 days) and 70 second-level (personal-level) responses in our analysis (repeated daily measures (days) were nested within individuals). The research model of the study is depicted in figure 1 . The mean age of respondents $(\mathrm{N}=70)$ was 35 (min. 23, max. 50), the average tenure of participants was approximately seven (min.1, max.30)

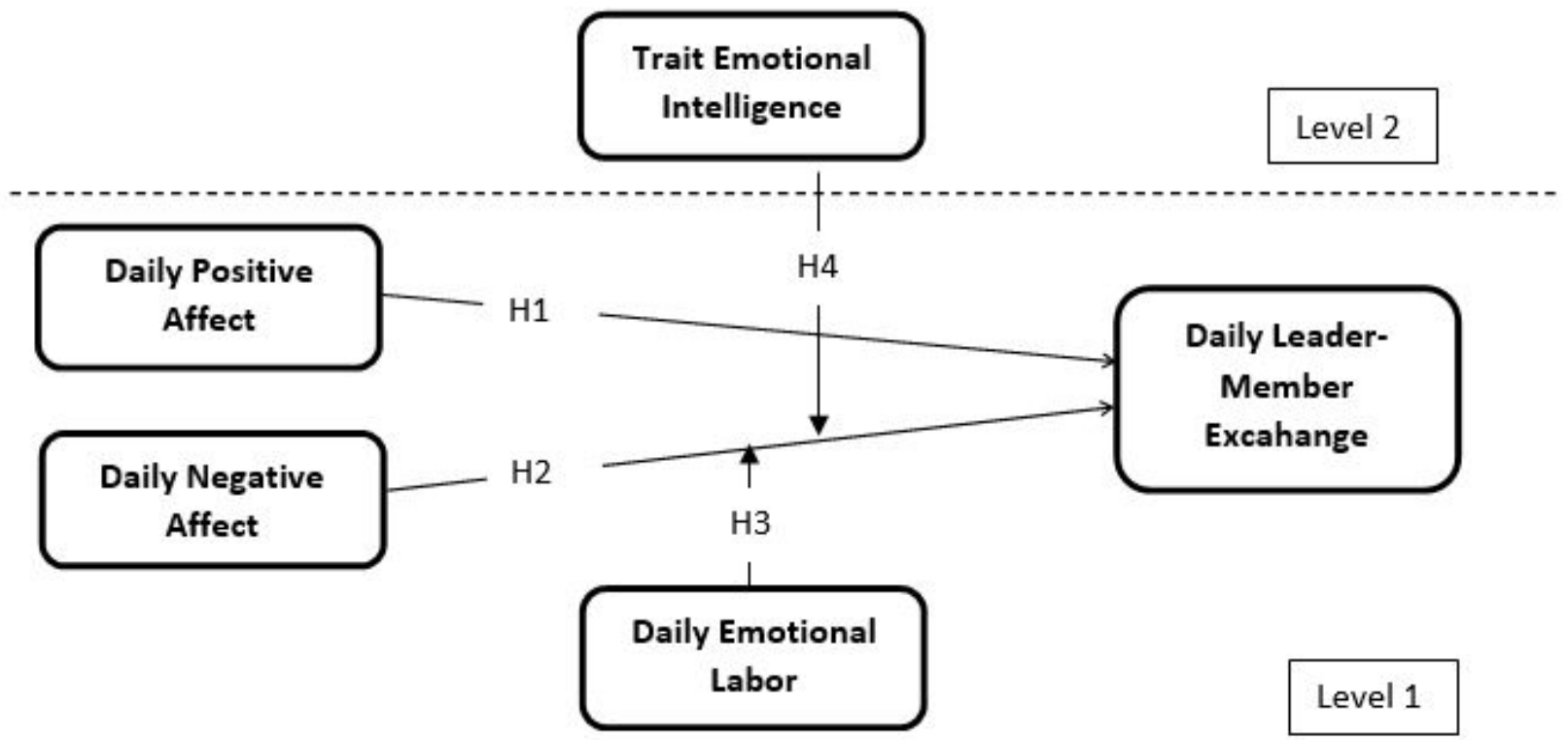

Figure 1: The Research Model of the Study

years, and 69\% were female. About $13 \%$ had a high school degree, 14\% completed vocational school, $41 \%$ completed graduate studies, and $32 \%$ completed post-graduate studies.

\subsection{Measures}

We chose the scales to assess the study variables through certain criteria. First, extant studies provided evidence for the reliability and validity of all measures. Second, measures were successfully used in several countries, and they were also validated to Turkish language and context by extant studies. Last, they were consistent and enabling for multilevel analysis. All reliability scores calculated for the scales were acceptable and high as presented under the "analysis and results" title in Table 1. All measures used in the study used a six-point Likert-type scale. All measures except the trait emotional intelligence questionnaire were daily surveys. Day-level scales were adapted (when necessary) with minor changes for capturing daily experiences (e.g., adding "today" or changing present tense to past tense). Original forms and slightly modified forms (for day level usage) are given in the appendix.
Positive and negative affect were measured using the PANAS scale developed by Watson et al. (1988) and validated for Turkey by Gençöz (2000). The original survey contains 20 items to assess NA and PA. Authors often prefer to select some of the items from the scales in daily and longitudinal research designs to keep the daily surveys as short as possible (e.g., Tadić et al., 2015; Tadić Vujčić et al., 2017). Items that are more relevant for the job nature of the sample and items that are more likely to happen on a daily basis with higher within-person variability (e.g., Wichers et al., 2012) are usually selected. Items with the highest factor loadings (e.g., Petrou et al., 2012) or items within a sub-cluster of the concept are also preferred (e.g., Ouyang et al., 2019). A review of the extant studies addressing the daily form of the concept also guides the formation of the structure. Following the aforementioned path, PA items were taken from pleasant activated (high activation) positive affect cluster (Watson \& Tellegen, 1985; Barrett \& Russell, 1998). Also, one item from each cluster (another classification) of PA (see Egloff et al., 2003), joy (enthusiastic), interest (strong), and activation (active) were taken for representativeness. Unpleasant activated (high activation) negative affect items ("distressed", "upset", "nervous", and "irritated") were used for assessing NA. 
The measure used a six-point scale ranging from "not at all" to "very often".

EL was assessed using the revised version of the Emotional Labor Scale developed by Brotheridge and Lee (2003) and revised by Lee and Brotheridge (2011) by changing the construct components from "deep acting" and "surface acting" to "deep acting", "hiding feelings", and "faking emotions". This version was tested for the Turkish context by Dursun et al. (2014). The original scale consists of 9 items ( 3 items for each dimension). Six items of the initial questionnaire ( 2 items with the highest factor loadings for each dimension) were used for measuring the variable. Each of the three subscales had two items. The sample items from this scale for deep acting is "Today I made an effort to actually feel the emotions that I need to display to others", for faking emotions "Today I pretended to have emotions that I didn't really have"; and for hiding feelings "Today I resisted to express my true feelings". The measure uses a six-point scale ranging from "not at all" to "very often".

Leader-Member Exchange was assessed using items from the LMX-7 scale that is developed by Scandura and Graen (1984). LMX-7 is a frequently used scale in the multilevel longitudinal analysis. Several studies (e.g., Gutermann et al., 2017) choose to use some of the items of the scale instead of giving all of the items due to feasibility reasons in multilevel studies. Three items with the highest factor loadings in the literature and the validation studies in the Turkish context were chosen from the original seven items (e.g., Joseph et al., 2011; Caliskan, 2015). A sample item from this scale is "How well did your leader understand your job problems and needs today?". The measure uses a six-point Likert-type scale ranging from "strongly disagree" to "strongly agree". In the current study, the reliabilities calculated for the measure were between .85 .89 across measurement days, indicating high reliabilities (Table 1).

The EI levels of the respondents were assessed by utilizing the short form of the Trait Emotional Intelligence
Questionnaire. The complete form (153 items) was developed by Petrides and Furnham (2000, 2001), and the short form (30 items) of the scale (Petrides, 2009) was validated for the Turkish by Deniz et al. (2013). As EI was measured in the person level with a one-time longer questionnaire, we used all 30 items (same as the original). Petrides (2009) and Petrides et al. (2010) provided adequate and high reliability scores (Cronbach's Alpha) for the short form scale (.69 and .87). Deniz et al. (2013) reported a .81 reliability score for the Turkish form of the scale. The measure adopts a six-point Likert scale ranging from "strongly disagree" to "strongly agree". The reliability score calculated for the scale in the present study was .85. In addition, we controlled our results for demographic variables; gender, age, education, and tenure.

\section{Results}

Demographic variables were used as second-level control variables in the current study. 70 respondents provided 350 day level (daily measures of PA, NA, EL, and LMX for five consecutive workdays) and 70 person level responses (EI and demographics). Respondents' ages were ranging between 23 to 50 (mean $=35$ ). Their tenure ranged between 1 to 30.48 of the 70 respondents were female. $73 \%$ completed a university or higher level degree.

We calculated reliability scores for the scales and their sub-dimensions that are used in the study. Within-person reliability may be misleading and tends to be high because of repeated measures. As a solution to this problem, some authors (e.g., Beal \& Ghandour, 2011) preferred to measure reliabilities of daily measures for each day the surveys were conducted. Following this approach, we calculated Cronbach's alpha scores of day-level variables for each measurement day. Reliabilities across days and variables varying from .647 to .924 support the reliability of the day-level measures (Table 1). Besides, the reliability scores for the trait EI scale (person-level) are within the expectable limits.

Table 1: Reliabilities of the measures

\begin{tabular}{|l|l|l|l|l|l|l|l|l|}
\hline Day & LMX & $\begin{array}{l}\text { Deep } \\
\text { Acting }\end{array}$ & $\begin{array}{l}\text { Faking } \\
\text { Emotions }\end{array}$ & $\begin{array}{l}\text { Hiding } \\
\text { Feelings }\end{array}$ & $\begin{array}{l}\text { Emotional } \\
\text { Labor }\end{array}$ & $\begin{array}{l}\text { Negative } \\
\text { Affect }\end{array}$ & $\begin{array}{l}\text { Positive } \\
\text { Affect }\end{array}$ & $\begin{array}{l}\text { Trait } \\
\text { Emotional } \\
\text { Intelligence }\end{array}$ \\
\hline 1 &, 857 &, 860 &, 924 &, 778 &, 860 &, 737 &, 843 \\
\hline 2 &, 861 &, 903 &, 815 &, 807 &, 878 &, 809 &, 778 & - \\
\hline 3 &, 855 &, 889 &, 757 &, 647 &, 873 &, 792 &, 756 &, 712 \\
\hline 4 &, 882 &, 859 &, 754 &, 734 &, 870 &, 801 &, & - \\
\hline 5 &, 857 &, 889 &, 861 &, 767 &, 871 &, 809 &, 860 & - \\
\hline Total &, 861 &, 879 &, 751 &, 824 &, 870 &, 792 &, 802 &, 851 \\
\hline
\end{tabular}

Note: reliabilities for day-level variables are calculated for each measurement day. Total reliabilities stand for reliabilities calculated for all day-level data $(\mathrm{N}=350)$. Trait emotional intelligence is measured for one time (person-level). 


\subsection{Correlations and Descriptive Statistics}

Day-level and person-level correlations and descriptive statistics are presented in Table 2. Standard deviations and correlations were calculated for person-level and day-level separately. Inter-individual correlations (person-level) were calculated by aggregating the five-day scores for each individual. The person-level variable EI was added by matching aggregated scores (across days) and person-level
EI. Intra-individual correlations were calculated via HLM by using the differences in the variance comparing when the level one predictor was included in the model and not included in the model (null model) for explaining the other level-one variable. The aggregated person-level analyses demonstrate that LMX is positively and significantly associated with PA, Deep acting, and trait EI while negatively and significantly linked with NA. Also, EI is significantly and positively related to PA (aggregated across five days).

Table 2: Descriptive statistics and between and within-individual correlations among study variables

\begin{tabular}{|l|l|l|l|l|l|l|l|l|l|r|}
\hline & Mean & SDw & SDb & 1 & 2 & 3 & 4 & 5 & 6 & 7 \\
\hline $\begin{array}{l}\text { 1. Leader-Member } \\
\text { Exchange }\end{array}$ & 3,60 & 1,19 &, 89 & &, 002 &, $149^{* *}$ &,- 028 &,$- 218^{* *}$ &, $418^{* *}$ &, $252^{*}$ \\
\hline 2. Faking Emotions & 2,28 & 1,13 &, 93 &, 052 & 1 &, $565^{* *}$ &, $699^{* *}$ &, $337^{* *}$ &,- 077 &,- 090 \\
\hline 3. Deep Acting & 2,99 & 1,32 & 1,10 &, 005 &, $245^{* *}$ & 1 &, $482^{* *}$ &, 105 &, 071 &, 015 \\
\hline 4. Hiding Feelings & 2,43 & 1,19 &, 98 &,- 053 &, $296^{* *}$ &, $194^{* *}$ & 1 &, $372^{* *}$ &,$- 142^{* *}$ &,- 208 \\
\hline 5. Negative Affect & 2,59 & 1,08 &, 83 &,- 040 &, 122 &,- 046 &, $133^{*}$ & 1 &,$- 363^{* *}$ &,- 170 \\
\hline 6. Positive Affect & 4,04 & 1,10 &, 83 &, $322^{* *}$ &,- 043 &,- 022 &,- 047 &,$- 311^{* *}$ & 1 &, $442^{* *}$ \\
\hline $\begin{array}{l}\text { 7. Trait Emotional } \\
\text { Intelligence (L2) }\end{array}$ & 4,48 & - &, 63 & - & - & - & - & - & - & 1 \\
\hline
\end{tabular}

Note: Correlations above the diagonal depict person-level correlations (means across days, $\mathrm{N}=70$ ). Correlations below the diagonal show day-level correlations calculated via HLM $(\mathrm{N}=350)$. $\mathrm{SDw}=$ Within-person standard deviation, $\mathrm{SDb}=$ Between-person standard deviation . LMX= Leader-Member Exchange. L2= Level 2

$* \mathrm{p}<0.05$ and $* * \mathrm{p}<0.01$

\subsection{Analysis}

In the current study, repeated daily measures (days) are nested within individuals (see, Nezlek \& Plesko, 2003; Xanthopoulou et al., 2008). To test our hypotheses, we utilized Hierarchical Linear Modelling Software (HLM), which is suitable for analyzing nested data. The Hierarchical Linear Modeling approach enables researchers to simultaneously test intra and inter-individual associations.

Before testing our hypotheses using a multilevel analysis design, we investigated if there was a significant intra-individual variance in the daily measured variables of the study. We created null models explaining each daily variable with only intercepts from two levels. The calculation of the percentages of intra-individual variance demonstrated that there was a substantial intra-individual level variance for all day-level variables, justifying and necessitating the multilevel analysis to test our hypotheses. $45 \%$ to $61 \%$ of the variance in the daily measured constructs was within-individuals (Table 3 ). Partitioning the variance of day-level variables showed that there is a significant amount of variation both for intra-individual and inter-individual levels.

\subsection{Tests of Hypotheses}

Following methodological suggestions in the literature (Peugh \& Enders, 2005; Enders \& Tofighi, 2007), studies investigating day level repeated data that are nested within-person, adopt group centering approach for the level 1 (day level) variables and grand centering for level 2 (person level) variables (e.g., Ilies et al., 2011; Tadić et al. 2015; Ouyang et al., 2019). Moreover, there is not only one best way for centering in nested models (Nezlek and Allen, 2006). The purpose of the analysis and the research design determine the centering method that should be used in the model. For testing the current study's general hypotheses, we chose to center level 1 variables on the respective person mean (group centered) and level 2 variables on the sample mean (group centered). Group centering level 1 variables allows us to understand the effects 
of the variance in how participants felt each day. In other words, this centering approach enables us to investigate the effect of variance in an individual's level of daily affect compared to the mean level of affect the same individual experiences on other days (the mean of the individual across measurement days - not the whole sample) on daily LMX. For instance, an employee may be experiencing higher or lower levels of NA/PA compared to others in general; still, what happens when the employee experienc- es higher or level NA/PA compared to his/her own average is another question. This approach allows us to see how does employees' LMX change on the days they feel higher NA/PA or lower NA/PA (independent from their variation from the sample). Thus, EL structures and daily affect variables were group-centered, and the person-level variable EI was grand centered. The dependent level-one variable LMX remained uncentered.

Table 3: Partitioning variance components of within-person variables

\begin{tabular}{|c|c|c|c|c|}
\hline Variable & Intercept & $\begin{array}{l}\text { Within-person } \\
\text { variance }\end{array}$ & $\begin{array}{l}\text { Between-person } \\
\text { variance }\end{array}$ & $\begin{array}{l}\text { Percent of Within-person } \\
\text { variance }\end{array}$ \\
\hline Leader-Member Exchange & $3.60 * *$ & 0.64 & 0.79 & 45 \\
\hline Positive Affect & $4.04 * *$ & 0.55 & 0.66 & 45 \\
\hline Negative Affect & $2.59 * *$ & 0.57 & 0.61 & 48 \\
\hline Faking Emotions & $2.28 * *$ & 0.75 & 0.53 & 59 \\
\hline Deep Acting & $2.99 * *$ & 1.07 & 0.69 & 61 \\
\hline Hiding Feelings & $2.43 * *$ & 0.92 & 0.76 & 55 \\
\hline
\end{tabular}

The percent of within-person variance was as computed as $\sigma 2 /(\sigma 2+\tau 00)$.

$* * \mathrm{p}<0.01$.

Hypothesis 1 suggested a positive link between daily PA and LMX, while hypothesis 2 suggested a negative association between daily NA and LMX. Hypothesis 3 predicted that EL moderates the relationship between NA and LMX. To test these hypotheses, a model with only person-level control variables, gender, age, tenure, education, and trait EI was created in the first step (Table 4). EI was entered as grand mean-centered. This model revealed that EI had a significant cross-level main effect on LMX $(B=0.40, p<0.05)$. None of the demographic control variables had any significant effects on the independent variable. In the second model, we added day-level variables with previous control variables. All day-level variables were group-centered. This way, by eliminating the potential effects of the difference between participants' means, the analysis demonstrated how the day-level intra-person change in the participants' NA, PA, and EL was associated with daily, intra-person changes in the LMX experience. PA significantly predicted LMX in the proposed way $(B=0.43, p<0.001)$, supporting the first hypothesis of the study. NA also demonstrated a positive and significant association with LMX $(B=0.10, p<0.05)$ in the opposite direction proposed by hypothesis 2 . None of the EL dimensions demonstrated significant direct effects on LMX. In model three, we tested the cross-level moderator effect of EI on PA and NA slopes. Trait EI showed no significant moderator effects. Hypothesis 4 was not supported. For level-one interaction effects (for the third hypothesis that suggests EL as a moderator on the relationship be- tween NA and LMX), we added product terms of NA and all EL dimensions. We multiplied standardized scores of each variable for creating product terms to avoid possible multicollinearity problems (Aiken \&West, 1991); thus we entered them as uncentered (as they were already centered) in the model. The interaction terms indicated no significant moderation. The moderation hypotheses regarding day-level variables were rejected for the intra-individual variance.

Results of correlation analysis demonstrated a negative link between NA and LMX on the aggregated level. Taken together with the results of regression analysis (through within-person variation), employees with higher NA levels (compared to others) have lower levels of LMX while they have higher levels of LMX on the days they feel higher NA (compared to their own NA mean). On the grounds of this pattern of results and research suggesting nonlinear links between NA and LMX (e.g., Hochwarter, 2005), we tested possible curvilinear effects of NA by adding NA square in the model after controlling for NA and second-level variables. U-shaped relationship regarding NA and LMX was not significant. Still, the curve estimation of the quadratic model for NA was significant. We tested whether the relationships regarding NA change when respondents experience high levels and low levels of NA. We created two different files by splitting through the responses lower and higher than the median of NA. For the low NA group, NA did not relate with LMX significantly. For the high NA group, NA was associated negatively and significantly 
Table 4: Multilevel estimates for models predicting the daily LMX

\begin{tabular}{|c|c|c|c|c|c|c|c|c|c|c|c|c|}
\hline \multirow[b]{2}{*}{ Variable } & \multicolumn{3}{|c|}{ Model 1} & \multicolumn{3}{|c|}{ Model II } & \multicolumn{3}{|c|}{ Model III } & \multicolumn{3}{|c|}{ Model IV } \\
\hline & Est & SE & $T$ & Est & SE & $\mathbf{T}$ & Est & SE & $\mathbf{T}$ & Est & SE & $t$ \\
\hline Intercept & 4.76 & 0.59 & $8.00 * *$ & 4.76 & 0.59 & $8.00 * *$ & 4.76 & 0.59 & $8.00 * *$ & 4.73 & 0.58 & $8.11 * *$ \\
\hline $\begin{array}{l}\text { Trait Emotional } \\
\text { Intelligence }\end{array}$ & 0.40 & 0.16 & $2.43^{*}$ & 0.40 & 0.16 & $2.43^{*}$ & 0.40 & 0.16 & $2.43^{*}$ & 0.40 & 0.16 & $2.50 *$ \\
\hline Faking Emotions & & & & -0.04 & 0.09 & -0.49 & -0.04 & 0.09 & -0.53 & -0.02 & 0.08 & -0.32 \\
\hline Deep Acting & & & & 0.05 & 0.07 & 0.75 & 0.05 & 0.07 & 0.74 & 0.05 & 0.07 & 0.82 \\
\hline Hiding Feelings & & & & -0.01 & 0.06 & -0.25 & 0.02 & 0.06 & 0.32 & 0.00 & 0.07 & 0.07 \\
\hline Negative Affect & & & & 0.10 & 0.04 & $2.42^{*}$ & 0.10 & 0.04 & $2.21^{*}$ & 0.10 & 0.04 & $2.03 *$ \\
\hline Positive Affect & & & & 0.43 & 0.05 & $7.72 * *$ & 0.42 & 0.05 & $7.82^{* * *}$ & 0.44 & 0.05 & $7.98^{* *}$ \\
\hline $\begin{array}{l}\text { Trait Emotional Intel- } \\
\text { ligence on Positive } \\
\text { Affect slope }\end{array}$ & & & & & & & -0.06 & 0.07 & -0.88 & & & \\
\hline $\begin{array}{l}\text { Trait Emotional Intel- } \\
\text { ligence on Negative } \\
\text { Affect slope }\end{array}$ & & & & & & & -0.00 & 0.06 & -0.06 & & & \\
\hline $\begin{array}{l}\text { Negative Affect*Fak- } \\
\text { ing Emotions }\end{array}$ & & & & & & & & & & -0.04 & 0.04 & -0.95 \\
\hline $\begin{array}{l}\text { Negative Af- } \\
\text { fect*Deep Acting }\end{array}$ & & & & & & & & & & 0.06 & 0.05 & 1.18 \\
\hline $\begin{array}{l}\text { Negative Affect*Hid- } \\
\text { ing Feelings }\end{array}$ & & & & & & & & & & 0.06 & 0.06 & -1.07 \\
\hline
\end{tabular}

Notes: $\mathrm{N}=$ All level 1 variables (except the dependent variable) were group centered relative to the individuals' means. Level 2 variables were entered grand mean. Interaction variables were standardized before multiplication. ${ }^{* *}{ }_{\mathrm{p}} \mathrm{p}<0.01,{ }^{*} \mathrm{p}<0.05$

Table 5: Multilevel estimates for predicting LMX for high NA cluster

\begin{tabular}{|l|l|l|}
\hline Variable & Est & T \\
\hline Main effects & & \\
\hline Intercept & 4.51 & $8.76^{* *}$ \\
\hline Faking Emotions & -0.18 & -0.89 \\
\hline Deep Acting & 0.09 & 0.05 \\
\hline Hiding Feelings & 0.31 & 1.60 \\
\hline Negative Affect & 0.29 & $-2.16^{*}$ \\
\hline Cross Level Interaction Trait Emotional Intelligence effect on & & $3.51^{* *}$ \\
\hline Intercept & \multicolumn{2}{|l}{} \\
\hline Negative Affect slope & 0.53 & -0.11 \\
\hline Level 1 Interaction & -0.01 & \\
\hline Negative Affect*Faking Emotions & & 0.45 \\
\hline Negative Affect*Deep Acting & 0.06 & $2.28^{*}$ \\
\hline Negative Affect*Hiding Feelings & 0.33 & $-2.03^{*}$ \\
\hline
\end{tabular}

Note: Analysis conducted in high-level Negative Affect group (responses higher than the median of Negative Affect across the sample). All predictor scores were grand mean centered to include interpersonal variance.

$* \mathrm{p}<0.05, * * \mathrm{p}<0.01$. 
with LMX. As we split the file through the occasions (not people) we used grand centering for testing the moderator hypotheses regarding the high-level NA group. The results were summarized in Table 5. NA was negatively related to LMX. EI showed no moderator effect on this relationship but had a direct cross-level effect on LMX. Deep acting and hiding feelings significantly moderated the relation- ship between NA and LMX.

To understand the nature of the moderation, we graphically depicted interaction effects by using one standard deviation above and below the mean for variables. The plots demonstrate that the negative relationship is stronger when participants experienced lower levels of deep acting and higher levels of hiding feelings.

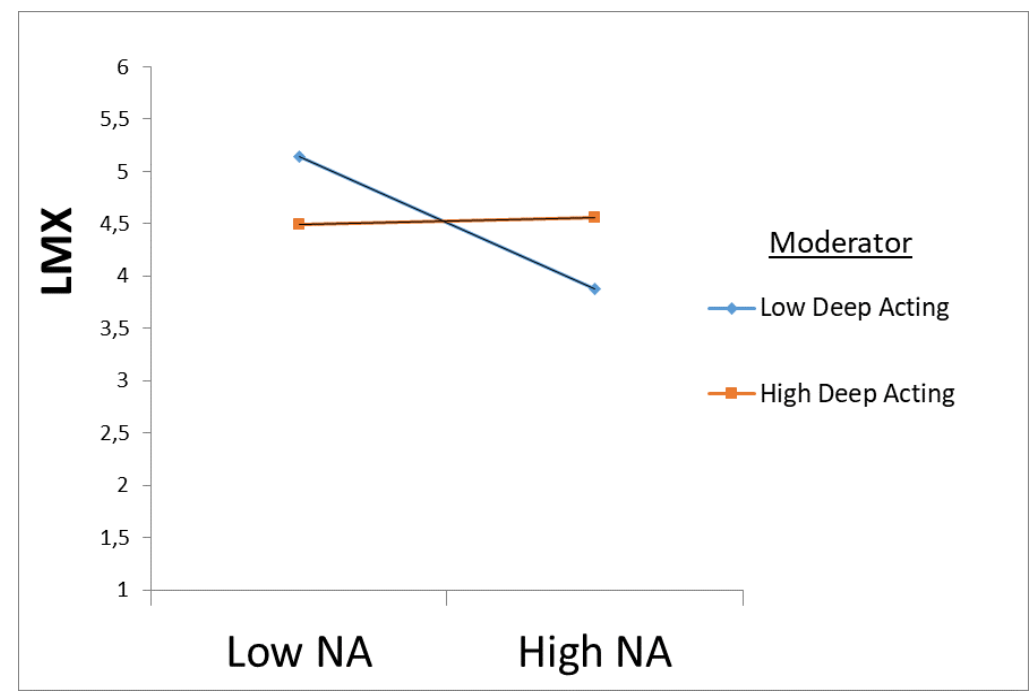

Figure 2: The first level moderating effect of deep acting for high NA sample.

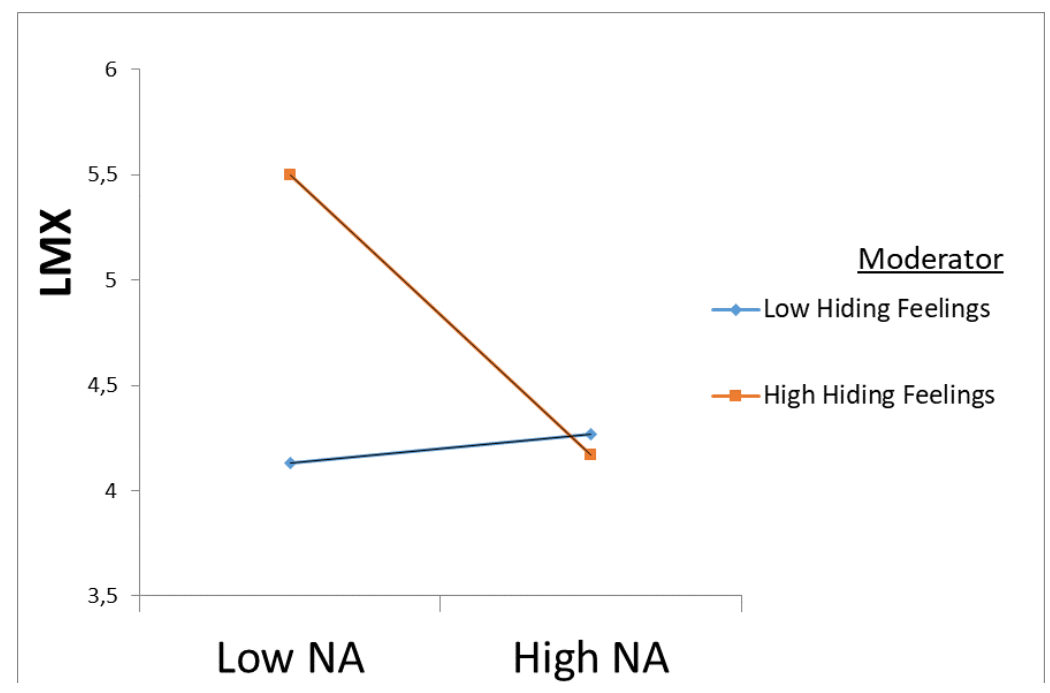

Figure 3: The first level moderating effect of hiding feelings for high NA sample 


\section{Discussion and Conclusion}

\subsection{Discussion}

This study investigated the association between daily affect and daily LMX and the moderator roles of EI and EL on this relationship. Seventy participants provided 70 person-level data (via a survey assessing demographics and EI) and 350 day level data (through a survey measuring daily forms of NA, PA, EL, and LMX for five consecutive days). Hypotheses were tested in a multilevel setting where the days were nested in employees.

The multilevel analysis results using group-centered level-one variables indicated that both PA and NA were positively related to the dependent variable. This means, on the days employees experienced higher levels of PA and NA, they also perceived higher levels of LMX. In other words, higher levels of daily NA and PA (compared to the mean of individuals' affect level across five days) increased the daily LMX experience. The PA part of these findings supports our propositions and is consistent with the extant literature (e.g., Hochwarter, 2005; Liu et al., 2020). However, the NA part of these findings contrasts with our propositions and most of the present research (e.g., Sniderman et al., 2016). This pattern of findings regarding the NALMX association can be explained by the Conservation of Resources Theory (Hobfoll, 2011) as the theory suggests that employees try to seek, increase and sustain resources in demanding situations. On the days employees feel higher NA levels, they seek quality leadership interaction to alter their resources. The study measured affect that can be caused by any life events and towards anything instead of solely assessing affect towards the leader. Employees can use LMX as a coping mechanism (Major \& Morganson, 2011) to reduce their NA produced by various factors. Besides, most studies that have addressed the relationship between NA and LMX did not adopt a multilevel within-person research design. Instead, they analyzed the between-person variance addressing the one-time measured general experience of NA and the general perception of LMX. Hence, the current study findings regarding the person-level (aggregated) NA and LMX are consistent with the general stream of findings in the literature (as they indicate a negative association). Moreover, investigation of daily intra-individual relationships between the constructs remains understudied, and findings of such research can provide new perspectives on the matter.

Findings underscore the fact that between-person and intra-person associations may operate in different ways. For instance, an employee may experience high-quality LMX in the days he/she feels comparatively higher affect, regardless of his/her between-person general affect or LMX level. The same person may face low-quality LMX than others when average scores are compared (inter-per- sonal level). Thus, between-person and intra-person variances can show different outcomes. Using a multilevel approach enabled us to investigate both variances that provide essential insights into how affect is related to LMX. Therefore, we also tested the relationships regarding the between-employee variance. The analysis conducted with the aggregated scores of days for each employee showed a pattern of result that is opposite to the findings gathered through within-person variances (group-mean centering). Employees experience lower levels of LMX in general when they have higher NA levels compared to others (person-level). In contrast, on the within-person level, they have higher levels of LMX on the days they experience higher NA.

Trait EI shows a direct positive cross-level impact on day-level LMX in this study. The employees with higher Trait EI experience significantly higher levels of daily LMX. However, despite its direct effect, Trait EI has no significant influence on the affect-LMX slopes. The extant EI literature either addresses LMX as an antecedent (e.g., Clarke \& Mahadi, 2011) or focuses on the leader's EI (e.g., Humphrey, 2012). Therefore, the current study's findings serve as a platform and a call for future research to enlighten the role of followers' EI on the affect-LMX association.

None of the EL constructs demonstrated any significant moderating effects in the preliminary analysis. However, when we tested for high NA and low NA groups separately, deep acting and hiding feelings showed significant moderation between NA and LMX in the proposed way. The independent testing of high and low affect levels may further enhance our understanding of the nature of their influence on the outcomes (e.g., Hochwarter, 2005). We tested the relationship between variables on the days NA was higher than the sample average, and on the days it was lower. The negative relationship was stronger when participants experienced lower levels of deep acting and higher levels of hiding feelings for the high NA sample. These findings align with the existing studies that reported significant links between EL and LMX (e.g., Liden \& Maslyn, 1998).

\subsection{Theoretical and Practical Implications}

This investigation contributes to current literature in several ways. First, the study furthers the knowledge on the affect-LMX relationship by shifting the search of causality by casting affect an antecedent role. It reveals that daily affective states significantly influence daily LMX. This is important to provide a platform and a call for more research to shed light on the affect-to-LMX pathway. Second, the study further elaborates the complex nature of the association between concepts as it demonstrates that 
they relate differently on the person and day level. This is critical because the extant knowledge regarding this relationship is dominantly a product of the general stream of findings addressing concepts as static structures and neglecting intra-individual variance. The current study also enhances the information about the affect-LMX link by demonstrating that high and low levels of affect can have different natures of associations with LMX. Moreover, the significance of the moderating roles of EL constructs can also be different in high and low levels of affect.

These findings provide significant managerial implications. Enhancing our knowledge of the antecedents of LMX is crucial for the performance of public health institutions. Recent studies conducted in the Turkish context (e.g., Ürek \& Uğurluoğlu, 2019) report findings that associate LMX with positive organizational outcomes in public healthcare organizations. The nature of the job and the workplace can elevate the levels of affect experienced by public health care professionals. Findings of the current study indicate that employees can seek and engage in higher levels of exchange with their leaders on the days they experience higher levels of both positive and negative affect. Leaders should acknowledge that and respond with higher leadership support and involvement. However, employees' general levels of affect act differently whereas positive affect increases LMX on the person-level, and negative affect is reversely related to LMX. Besides, the intensity of negative affect can impact LMX in different ways, and these effects are regulated by EL. When negative affect is high, employees experience lower LMX if they choose to hide their emotions. Contrary, deep acting weakens the adverse association between negative affect and LMX. Therefore, efforts encouraging deep acting can mitigate the undesirable impact of negative affect on LMX. The findings of the present study underscore the HRM practices that address the usage of more positive emotional regulation styles, such as training and development efforts and workplace counseling. Also, strengthening leadership development processes for fostering leadership styles that would provide better LMX quality by including daily emotions such as emphatic leadership (Kock et al., 2019) can serve as a significant HRM policy. Creating a positive climate where employees do not hide their feelings and supporting the psychological capacities of employees for constructive regulation of emotions can alleviate the effects of negative affect on LMX. Given the positive cross-level effects trait EI on daily LMX, investing in the EI capacities and including EI as a selection criterion in recruitment processes can enhance LMX in organizations.

\subsection{Limitations and Directions for Future Research}

The study data was provided by the employees working in the public health organization in Turkey. Due to difficulties in data collection for daily multilevel research designs, we could not enlarge our sample to other work settings. Readers should consider this for the generalizability of the findings. In a cross-cultural study (among ten countries), Aycan et al. (2000) presented that managers' assumptions regarding HRM practices and employee characteristics are significantly affected by the culture. The study also revealed that Turkey depicts a highly paternalistic culture that can affect perceptions such as loyalty and malleability, which are essential aspects of LMX development. Thus, the findings of the current should be considered with the cultural characteristics of the sample. Tightly-knit and close relational characteristics build on loyalty and paternalism can strengthen the bonds between leaders and members, fostering the crossover or effects of daily affect on LMX.

All the variables analyzed in this research were assessed through self-rating measures. Although using group-centered forms of these variables eliminated the between-person variance, self-rating may create biases, especially for grand-mean centered forms of the variables. Despite two week-gap between the person-level general questionnaire and the first day-level questionnaire, all day-level measures were given daily together. As the scale was kept very short and daily research designs are demanding for respondents, we did not separate the daily measures (for each variable) or give them at different times during the days. This can create suspicions for common method bias. For that reason, we conducted Harman's single factor test. When daily measures were allowed to factor freely, they explained $68 \%$ of the variance, and when they were forced to factor under one factor, they could only explain $27 \%$ of the variance. One factor structure explaining less than $50 \%$ (threshold) of the variance indicates no problems regarding common method bias (Eichhorn, 2014).

The study data was collected from one unit; therefore, team-level variances could not be reflected in our research design. For further studies, three-level research designs including organizational units may enhance our knowledge of the relationship between affect and LMX.

\subsection{Conclusion}

The investigation of LMX in public healthcare organizations is crucial because LMX serves as a significant predictor for several organizational and individual outcomes. The affective pathway to LMX is significant and complex. Affect relates to LMX differently at intra-individual and inter-individual levels. Besides, high and low affect levels can demonstrate different patterns of associations with LMX when the affective moderators are included in the model. The findings of the current study underscore the sophisticated nature of the affect-LMX relationship and the significance of further research on the matter. 


\section{Literature}

Aiken, L. S., West, S. G., \& Reno, R. R. (1991). Multiple regression: Testing and interpreting interactions. sage.

Ardabili, F. S. (2020). Moderating-mediating Effects of Leader Member Exchange, Self-efficacy and Psychological Empowerment on Work Outcomes among Nurses. Organizacija, 53(3), 246-258. https://doi. org/10.2478/orga-2020-0016

Ashton-James, C. E., \& Ashkanasy, N. M. (2008). Chapter 1 Affective events theory: a strategic perspective. In Research on Emotion in Organizations, 4(1), 1-34. https://doi.org/10.1016/S1746-9791(08)04001-7

Aycan, Z., Kanungo, R., Mendonca, M., Yu, K., Deller, J., Stahl, G., \& Kurshid, A. (2000). Impact of culture on human resource management practices: A 10-country comparison. Applied Psychology, 49(1), 192-221. https://doi.org/10.1111/1464-0597.00010

Barrett, L. F., \& Russell, J. A. (1998). Independence and Bipolarity in the Structure of Current Affect. Journal of Personality and Social Psychology, 74(4), 967-984. https://doi.org/10.1037/0022-3514.74.4.967

Beal, D. J., \& Ghandour, L. (2011). Stability, change, and the stability of change in daily workplace affect. Journal of Organizational Behavior, 32(4), 526-546. https://doi.org/10.1002/job.713

Bener, A., N. Alayoglu, F. Çatan, P. Torun, and E. S. Yilmaz. (2019). Health Services Management in Turkey: Failure or Success?. International journal of preventive medicine 10(2019): 30. https://doi.org/10.4103/ ijpvm.ijpvm 42217

Bernerth, J. B., Ärmēnakis, A. A., Feild, H. S., Giles, W. F., \& Jack Walker, H. (2007). Is personality associated with perceptions of LMX? An empirical study. Leadership \& Organization Development Journal, 28(7), 613631. https://doi.org/10.1108/01437730710823879

Brief, A. P., \& Weiss, H. M. (2002). Organizational Behavior: Affect in the Workplace. Annual Review of Psychology, 53(1), 279-307. https://doi.org/10.1146/ annurev.psych.53.100901.135156

Brotheridge, C. M., \& Lee, R. T. (2003). Development and validation of the emotional labour scale. Journal of Occupational and Organizational Psychology, 76(3), 365379. https://doi.org/10.1348/096317903769647229

Caliskan, G. (2015). An examination of coach and player relationships according to the adapted LMX 7 scale: A validity and reliability study. Measurement in Physical Education and Exercise Science, 19(1), 22-33. https:// doi.org/10.1080/1091367x.2014.977996

Clarke, N., \& Mahadi, N. (2011). Chapter 9 Emotional Intelligence as a Moderator of the Quality of Leader-Member Exchange and Work-Related Outcomes. In What Have We Learned? Ten Years On (pp. 227254). Emerald Group Publishing Limited. https://doi. org/10.1108/s1746-9791(2011)0000007014

Costakis, H. R., Gruhlke, H., \& Su, Y. (2021). Implications of emotional labor on work outcomes of service workers in not-for-profit human service organizations. $\mathrm{Hu}$ man Service Organizations: Management, Leadership \& Governance, 45(1), 29-48. https://doi.org/10.1080/2 3303131.2020 .1818157
Cropanzano, R., Anthony, E. L., Daniels, S. R., \& Hall, A. V. (2017a). Social exchange theory: A critical review with theoretical remedies. Academy of Management Annals, 1(1), 479-516. https://doi.org/10.5465/ annals.2015.0099

Cropanzano, R., Dasborough, M. T., \& Weiss, H. M. (2017b). Affective events and the development of leader-member exchange. Academy of Management Review, 42(2), 233-258. https://doi.org/10.5465/ amr.2014.0384

Dansereau, F., Graen, G., \& Haga, W. J. (1975). A vertical dyad linkage approach to leadership within formal organizations. Organizational Behavior and Human Performance, 13(1), 46-78. https://doi.org/10.1016/00305073(75)90005-7

Dasborough, M. T. (2006). Cognitive asymmetry in employee emotional reactions to leadership behaviors. Leadership Quarterly, 17(2), 163-178. https://doi. org/10.1016/j.leaqua.2005.12.004

Deniz, M. E., Özer, E., \& Isik, E. (2013). Trait emotional intelligence questionnaire-short form: Validity and reliability studies. Egitim ve Bilim, 38(169).

Dienesch, R. M., \& Liden, R. C. (1986). Leader-Member Exchange Model of Leadership: A Critique and Further Development. Academy of Management Review, 11(3), 618-634. https://doi.org/10.5465/amr.1986.4306242

Dulebohn, J. H., Bommer, W. H., Liden, R. C., Brouer, R. L., \& Ferris, G. R. (2012). A Meta-Analysis of Antecedents and Consequences of Leader-Member Exchange. Journal of Management, 38(6), 1715-1759. https://doi.org/10.1177/0149206311415280

Dundar, M., Uzak, A. S., \& Karabulut, Y. (2010). Healthcare in overview of Turkey. EPMA Journal, 1(4), 587594. https://doi.org/10.1007/s13167-010-0049-7

Dursun, S., Aytaç, S., \& Bayram, N. (2014). Duygusal Emek Ölçeği Türkçe Formunun Geçerlilik Ve Güvenilirlik Çalışması. (Validation and Reliability Study of the Turkish Form of the Emotional Labor Scale) $\dot{I} s ̧-G \ddot{u} c ̧$ Endüstri İlişkileri ve Insan Kaynakları Dergisi, 1683, 10-18. https://doi.org/10.4026/1303-2860.2014.0252

Egloff, B., Schmukle, S. C., Burns, L. R., Kohlmann, C. W., \& Hock, M. (2003). Facets of dynamic positive affect: differentiating joy, interest, and activation in the positive and negative affect schedule (PANAS). Journal of personality and social psychology, 85(3), 528. https://doi.org/10.1037/0022-3514.85.3.528

Eichhorn, B. R. (2014). Common method variance techniques. Cleveland State University, Department of Operations \& Supply Chain Management. Cleveland, OH: SAS Institute Inc, 1-11.

Ellis, A. M., Bauer, T. N., Erdogan, B., \& Truxillo, D. M. (2019). Daily perceptions of relationship quality with leaders: implications for follower well-being. Work and Stress, 33(2), 119-136. https://doi.org/10.1080/02 678373.2018 .1445670

Enders, C. K., \& Tofighi, D. (2007). Centering predictor variables in cross-sectional multilevel models: A new look at an old issue. Psychological Methods, 12, 121138. https://doi.org/10.1037/1082-989x.12.2.121

Fouquereau, E., Morin, A. J. S., Lapointe, É., Mokounkolo, R., \& Gillet, N. (2019). Emotional labour profiles: 
Associations with key predictors and outcomes. Work and Stress, 33(3), 268-294. https://doi.org/10.1080/02 678373.2018.1502835

Freudenthaler, H. H., \& Neubauer, A. C. (2007). Measuring emotional management abilities: Further evidence of the importance to distinguish between typical and maximum performance. Personality and Individual Differences, 42(8), 1561-1572. https://doi. org/10.1016/j.paid.2006.10.031

Gençöz, T. (2000). Positive and Negative Affect Schedule: A study of validity and reliability. Türk Psikoloji Dergisi.

Glasø, L., Skogstad, A., Notelaers, G., \& Einarsen, S. (2018). Leadership, affect and outcomes: symmetrical and asymmetrical relationships. Leadership and Organization Development Journal. https://doi.org/10.1108/ LODJ-08-2016-0194

Grandey, A. A. (2000). Emotion regulation in the workplace: a new way to conceptualize emotional labor. Journal of Occupational Health Psychology, 5(1), 95110. https://doi.org/10.1037//1076-8998.5.1.95

Gutermann, D., Lehmann-Willenbrock, N., Boer, D., Born, M., \& Voelpel, S. C. (2017). How leaders affect followers' work engagement and performance: Integrating leader- member exchange and crossover theory. British Journal of Management, 28(2), 299-314. https://doi.org/10.1111/1467-8551.12214

Hobfoll, S. E. (2011). Conservation of resource caravans and engaged settings. Journal of occupational and organizational psychology, 84(1), 116-122. https://doi. org/10.1111/j.2044-8325.2010.02016.x

Hochschield, A. R. (1983). The Managed Heart. Working in America: Continuity, Conflict, and Change in a New Economic Era.

Hochwarter, W. (2005). LMX and job tension: Linear and non-linear effects and affectivity. Journal of Business and Psychology, 19(4), 505-520. https://doi. org/10.1007/s10869-005-4522-6

Hofmans, J., Dóci, E., Solinger, O. N., Choi, W., \& Judge, T. A. (2019). Capturing the dynamics of leader-follower interactions: Stalemates and future theoretical progress. Journal of Organizational Behavior, 40(3), 382-385. https://doi.org/10.1002/job.2317

Humphrey, R. H. (2012). How do leaders use emotional labor?. Journal of Organizational Behavior, 33(5), 740744. https://doi.org/10.1002/job.1791

Ilies, R., Johnson, M. D., Judge, T. A., \& Keeney, J. (2011). A within-individual study of interpersonal conflict as a work stressor: Dispositional and situational moderators. Journal of Organizational Behavior, 32(1), 4464. https://doi.org/10.1002/job.677

Jordan, P. J., \& Troth, A. (2011). Emotional intelligence and leader member exchange: The relationship with employee turnover intentions and job satisfaction. Leadership and Organization Development Journal, 32(3), 260-280. https://doi.org/10.1108/01437731111123915

Joseph, D. L., Newman, D. A., \& Sin, H. P. (2011). Leader-Member Exchange (LMX) measurement: evidence for consensus, construct breadth, and discriminant validity. In Building methodological bridges. Emerald Group Publishing Limited. https://doi.org/10.1108/ s1479-8387(2011)0000006012

Kock, N., Mayfield, M., Mayfield, J., Sexton, S., \& De La Garza, L. M. (2019). Empathetic leadership: How leader emotional support and understanding influences follower performance. Journal of Leadership \& Organizational Studies, 26(2), 217-236. https://doi. org/10.1177/1548051818806290

Lee, L., \& Madera, J. M. (2019). A systematic literature review of emotional labor research from the hospitality and tourism literature. International Journal of Contemporary Hospitality Management, 31(7), 28082826. https://doi.org/10.1108/IJCHM-05-2018-0395

Lee, M., Mayfield, C. O., Hinojosa, A. S., \& Im, Y. (2018). A Dyadic Approach to Examining the Emotional Intelligence-Work Outcome Relationship: The Mediating Role of LMX. Organization Management Journal, 15(1), 1-16. https://doi.org/10.1080/15416518.2018.1 427539

Lee, R. T., \& Brotheridge, C. M. (2011). Words from the heart speak to the heart. Career Development International, 16(4), 401-420. https://doi. org/10.1108/13620431111158805

Li, M., Pérez-Díaz, P. A., Mao, Y., \& Petrides, K. V. (2018). A Multilevel Model of Teachers' Job Performance: Understanding the Effects of Trait Emotional Intelligence, Job Satisfaction, and Organizational Trust. Frontiers in Psychology, 9, 1-13. https://doi. org/10.3389/fpsyg.2018.02420

Liden, R. C., \& Maslyn, J. M. (1998). Multidimensionality of leader-member exchange: An empirical assessment through scale development. Journal of Management, 24(1), 43-72. https://doi.org/10.1016/ s0149-2063(99)80053-1

Liu, C., Xu, D., Wang, C., Zhang, C., \& Qi, W. (2020). Can Positive Emotion Benefit to Leader-Member Exchange? The Role of Leader Identification. In 2020 International Conference on Wireless Communications and Smart Grid (ICWCSG) (pp. 412-415). IEEE. https://doi.org/10.1109/icwesg50807.2020.00094

Major, D. A., \& Morganson, V. J. (2011). Coping with work-family conflict: A leader-member exchange perspective. Journal of Occupational Health Psychology, 16(1), 126-138 https://doi.org/10.1037/a0021727

Mayer, J. D., \& Salovey, P. (1997). What is Emotional Intelligence? In P. and Salovey \& D. J. Sluyter (Eds.), Emotional Development and Emotional Intelligence: Educational Implications (pp. 3-31). New York: Basic Books. https://doi.org/10.1037/t05047-000

Medler-Liraz, H. (2014). Negative affectivity and tipping: The moderating role of emotional labor strategies and leader-member exchange. International Journal of Hospitality Management, 36, 63-72. https://doi. org/10.1016/j.ijhm.2013.08.010

Miao, C., Humphrey, R. H., \& Qian, S. (2020). The cross-cultural moderators of the influence of emotional intelligence on organizational citizenship behavior and counterproductive work behavior. Human Resource Development Quarterly, 31(2), 213-233. https://doi. org/10.1002/hrdq. 21385

Morris, J. A., \& Feldman, D. C. (1996). The dimensions, antecedents, and consequences of emotional 
labor. Academy of Management Review, 21(4), 9861010. https://doi.org/10.5465/amr.1996.9704071861

Nahrgang, J. D., \& Seo, J. J. (2016). How and Why High Leader-Member Exchange (LMX) Relationships Develop: Examining the Antecedents of LMX. In The Oxford Handbook of Leader-Member Exchange. https:// doi.org/10.1093/oxfordhb/9780199326174.013.3

Nezlek, J. B., \& Allen, M. R. (2006). Social support as a moderator of day-to-day relationships between daily negative events and daily psychological well-being. European Journal of Personality: Published for the European Association of Personality Psychology, 20(1), 53-68. https://doi.org/10.1002/per.566

Nezlek, J. B., \& Plesko, R. M. (2003). Affect-and self-based models of relationships between daily events and daily well-being. Personality and Social Psychology Bulletin, 29(5), 584-596. https://doi. org/10.1177/0146167203029005004

O’Connor Jr, R. M., \& Little, I. S. (2003). Revisiting the predictive validity of emotional intelligence: Self-report versus ability-based measures. Personality and Individual differences, 35(8), 1893-1902. https://doi. org/10.1016/s0191-8869(03)00038-2

Ouyang, K., Cheng, B. H., Lam, W., \& Parker, S. K. (2019). Enjoy your evening, be proactive tomorrow: How off-job experiences shape daily proactivity. Journal of Applied Psychology, 104(8), 1003. https://doi. org/10.1037/ap10000391

Petrides, K. V. (2009). Psychometric properties of the trait emotional intelligence questionnaire (TEIQue). In $A s$ sessing emotional intelligence (pp. 85-101). Springer, Boston, MA. 85-101 https://doi.org/10.1007/978-0387-88370-0 5

Petrides, K. V., \& Furnham, A. (2000). On the dimensional structure of emotional intelligence. Personality and Individual Differences, 29, 313-320. https://doi. org/10.1016/s0191-8869(99)00195-6

Petrides, K. V., \& Furnham, A. (2001). Trait emotional intelligence: Psychometric investigation with reference to established trait taxonomies. European Journal of Personality, 15(6), 425-448. https://doi.org/10.1002/ per.416

Petrides, K. V., Vernon, P. A., Schermer, J. A., Ligthart, L., Boomsma, D. I., \& Veselka, L. (2010). Relationships between trait emotional intelligence and the Big Five in the Netherlands. Personality and Individual Differences, 48, 906-910. https://doi.org/10.1016/j. paid.2010.02.019

Petrou, P., Demerouti, E., Peeters, M. C., Schaufeli, W. B., \& Hetland, J. (2012). Crafting a job on a daily basis: Contextual correlates and the link to work engagement. Journal of Organizational Behavior, 33(8), 1120-1141. https://doi.org/10.1002/job.1783

Peugh, J. L., \& Enders, C. K. (2005). Using the SPSS mixed procedure to fit cross-sectional and longitudinal multilevel models. Educational and Psychological Measurement, 65(5), 717-741. doi:10.1177/0013164405278558

Scandura, T. A., \& Graen, G. B. (1984). Moderating effects of initial leader-member exchange status on the effects of a leadership intervention. Journal of applied psychology, 69(3), 428. https://doi.org/10.1037/0021-
9010.69.3.428

Shickle, D., Day, M., Smith, K., Zakariasen, K., Moskol, J., \& Oliver, T. (2014). Mind the public health leadership gap: the opportunities and challenges of engaging high-profile individuals in the public health agenda. Journal of Public Health, 36(4), 562-567. https:// doi.org/10.1093/pubmed/fdu003

Sniderman, P., Fenton-O'Creevy, M., \& Searle, R. (2016). Effects of managerial communication as moderated by LMX and trait NA. Journal of Managerial Psychology, 31(6), 1074-1090. https://doi.org/10.1108/jmp-042015-0120

Tadić Vujčić, M., Oerlemans, W. G., \& Bakker, A. B. (2017). How challenging was your work today? The role of autonomous work motivation. European Journal of Work and Organizational Psychology, 26(1), 8193. https://doi.org/10.1080/1359432x.2016.1208653

Tadić, M., Bakker, A. B., \& Oerlemans, W. G. (2015). Challenge versus hindrance job demands and well-being: A diary study on the moderating role of job resources. Journal of Occupational and Organizational Psychology, 88(4), 702-725. https://doi.org/10.1111/ joop. 12094

Tellegen, A., Watson, D., \& Clark, L. A. (1999). On the Dimensional and Hierarchical Structure of Affect. Psychological Science, 10(4), 297-303. https://doi. org/10.1111/1467-9280.00157

Troth, A. C., Lawrence, S. A., Jordan, P. J., \& Ashkanasy, N. M. (2018). Interpersonal Emotion Regulation in the Workplace: A Conceptual and Operational Review and Future Research Agenda. International Journal of Management Reviews, 20(2), 523-543. https://doi. org/10.1111/ijmr.12144

Tse, H. H. M., Dasborough, M. T., \& Ashkanasy, N. M. (2008). A multi-level analysis of team climate and interpersonal exchange relationships at work. The Leadership Quarterly, 19(2), 195-211. https://doi. org/10.1016/j.leaqua.2008.01.005

Tse, H. H. M., Troth, A. C., Ashkanasy, N. M., \& Collins, A. L. (2018). Affect and leader-member exchange in the new millennium: A state-of-art review and guiding framework. Leadership Quarterly, 29(1), 135-149. https://doi.org/10.1016/j.leaqua.2017.10.002

Uhl-Bien, M., Riggio, R. E., Lowe, K. B., \& Carsten, M. K. (2014). Followership theory: A review and research agenda. The Leadership Quarterly, 25(1), 83-104. https://doi.org/10.1016/j.leaqua.2013.11.007

Ürek D., \& Uğurluoğlu Ö. (2019). Examining the Impact of Leader-Member Exchange on Organizational Citizenship Behaviour in Healthcare Sector. Iş ve Insan Dergisi, 6(1), 81-92.

Wang, H., Hall, N. C., \& Taxer, J. L. (2019). Antecedents and Consequences of Teachers' Emotional Labor: a Systematic Review and Meta-analytic Investigation. Educational Psychology Review. 1-36 https://doi. org/10.1007/s10648-019-09475-3

Warwick, J., \& Nettelbeck, T. (2004). Emotional intelligence is...?. Personality and Individual Differences, 37(5), 1091-1100. https://doi.org/10.1016/j. paid.2003.12.003

Watson, D., \& Tellegen, A. (1985). Toward a consensual 
structure of mood. Psychological Bulletin, 98(2), 219. https://doi.org/10.1037/0033-2909.98.2.219

Watson, D., Clark, L. A., \& Carey, G. (1988). Positive and Negative Affectivity and Their Relation to Anxiety and Depressive Disorders. Journal of Abnormal Psychology, 97(3), 346-353. https://doi.org/10.1037/0021843X.97.3.346

Weiss, H. M., \& Cropanzano, R. S. (1996). Affective events theory: A theoretical discussion of the structure, causes and consequences of affective experiences at Work. In Research in organizational Behavior, 18(1), 1-74). https://doi.org/1-55938-938-9

Wen, J., Huang, S., \& Hou, P. (2019). Emotional intelligence, emotional labor, perceived organizational support, and job satisfaction: A moderated mediation model. International Journal of Hospitality Management, 81(December 2018), 120-130. https://doi. org/10.1016/j.ijhm.2019.01.009

Wichers, M., Peeters, F., Rutten, B. P., Jacobs, N., Derom, C., Thiery, E., ... \& van Os, J. (2012). A time-lagged momentary assessment study on daily life physical activity and affect. Health Psychology, 31(2), 135. https://doi.org/10.1037/a0025688

Xanthopoulou, D., Baker, A. B., Heuven, E., Demerouti, E., \& Schaufeli, W. B. (2008). Working in the sky: a diary study on work engagement among flight attendants. Journal of Occupational Health Psychology, 13(4), 345. https://doi.org/10.1037/10768998.13.4.345

Xu, S. T., Cao, Z. C., \& Huo, Y. (2020). Antecedents and outcomes of emotional labour in hospitality and tourism: A meta-analysis. Tourism Management, 79, 104099. https://doi.org/10.1016/j.tourman.2020.104099
Mehmet Çetin, $\mathrm{PhD}$ in organizational behavior. Currently works as an academician and the vice manager of the Graduate Education Institute in Istanbul Sabahattin Zaim University. He has ten years of academic experience. He also has worked as a strategic management consultant. His primary research areas are leadership, wellbeing, workplace spirituality, organizational culture, proactive behavior, and workplace loneliness.

Gulmira Samenova, PhD candidate at Istanbul Sabahattin Zaim University. She has extensive practical knowledge in the business and management of trade companies. Her areas of interest include leadership, HRM, marketing management, and business processes in agricultural enterprises.

Filiz Türkkan, PhD candidate, continues her education at Istanbul Sabahattin Zaim University Business Administration Doctorate Program. She currently works as a Branch Manager in Küçükçekmece District Health Directorate. She produces academic work on management and organization, organizational behavior, public health, and quality management.

Ceylan Karataş, PhD student, continues her education at Istanbul Sabahattin Zaim University Business Administration Doctorate Program. She works as the Deputy Manager of Administrative and Financial Services at a city Hospital. She conducts research on organizational behavior, public health, management, and organization. 


\section{Appendix A: Leader Member Exchange Questionnaire - Scandura and Graen (1984)}

The original items ( 3 of the total 7)

Instructions: This questionnaire contains items that ask you to describe your relationship with either your leader or one of your subordinates. For each of the items, indicate the degree to which you think the item is true for you by circling one of the responses that appear below the item.

1. How well does your leader (follower) understand your job problems and needs?

2. How well does your leader (follower) recognize your potential?

3. How would you characterize your working relationship with your leader (follower)?

Slightly Modified (for day level use) Versions Used in the Study (moditifations are in italics):

Instructions: This questionnaire contains items that ask you to describe your relationship with your leader. For each of the items, indicate the degree to which you think the item is true for you by circling one of the responses that appear below the item. Please consider your relationship with your leader today (not in general).

1. How well did your leader understand your job problems and needs today?

2. How well did your leader recognize your potential today?

3. How would you characterize your working relationship with your leader today?

\section{Appendix B: Emotional Labor Questionnaire - Lee \& Brotheridge (2011)}

The original items:

1. Pretend to have emotions that I don't really have

2. Show emotions that are expected rather than what I feel

3. Really try to feel the emotions I have to show as part of my job

4. Make an effort to actually feel the emotions that I need to display to others

5. Hide my true feelings about a situation

6. Resist expressing my true feelings

Slightly Modified (for day level use) Versions Used in the Study (moditifations are in italics):

1. Today I pretended to have emotions that I didn't really have

2. Today I showed emotions that are expected rather than what I feel

3. Today I really tried to feel the emotions I have to show as part of my job

4. Today I made an effort to actually feel the emotions that I need to display to others

5. Today I hided my true feelings about a situation

6. Today I resisted expressing my true feelings 


\section{Appendix C: Positive Affect Negative Affect Scale - PANAS - Watson et al. (1988)}

Just the wording in the instructions was modified to ask the frequency regarding today.

1. Distressed

2. Upset

3. Enthusiastic

4. Nervous

5. Irritated

6. $\quad$ Strong

7. Active

\section{Appendix D: Trait Emotional Intelligence Questionnaire- TEIQue-SF - (Person level) Petrides \& Furnham (2001), Petrides (2009)}

Just the wording in the instructions was modified to ask the frequency regarding today.

1. Expressing my emotions with words is not a problem for me.

2. I often find it difficult to see things from another person's viewpoint.

3. On the whole, I'm a highly motivated person.

4. I usually find it difficult to regulate my emotions.

5. I generally don't find life enjoyable.

6. I can deal effectively with people.

7. I tend to change my mind frequently.

8. Many times, I can't figure out what emotion I'm feeling.

9. I feel that I have a number of good qualities.

10. I often find it difficult to stand up for my rights.

11. I'm usually able to influence the way other people feel.

12. On the whole, I have a gloomy perspective on most things.

13. Those close to me often complain that I don't treat them right.

14. I often find it difficult to adjust my life according to the circumstances.

15. On the whole, I'm able to deal with stress.

16. I often find it difficult to show my affection to those close to me.

17. I'm normally able to "get into someone's shoes" and experience their emotions.

18. I normally find it difficult to keep myself motivated.

19. I'm usually able to find ways to control my emotions when I want to.

20. On the whole, I'm pleased with my life.

21. I would describe myself as a good negotiator.

22. I tend to get involved in things I later wish I could get out of.

23. I often pause and think about my feelings.

24. I believe I'm full of personal strengths.

25. I tend to "back down" even if I know I'm right.

26. I don't seem to have any power at all over other people's feelings.

27. I generally believe that things will work out fine in my life.

28. I find it difficult to bond well even with those close to me.

29. Generally, I'm able to adapt to new environments.

30. Others admire me for being relaxed. 